\title{
Universiteit
}

Leiden

The Netherlands

\section{Quantity systems and the count/mass distinction} Doetjes, J.S.; Filip, H.

\section{Citation}

Doetjes, J. S. (2021). Quantity systems and the count/mass distinction. In H. Filip (Ed.), Countability in Natural Language (pp. 52-84). Cambridge: Cambridge University Press. doi:10.1017/9781316823774.004

Version: $\quad$ Publisher's Version

License: $\quad$ Licensed under Article 25fa Copyright Act/Law (Amendment Taverne)

Downloaded from: https://hdl.handle.net/1887/3221254

Note: To cite this publication please use the final published version (if applicable). 


\title{
2 Quantity Systems and the Count/Mass Distinction
}

\author{
Jenny Doetjes
}

\subsection{The Nature of the Count/Mass Distinction}

When investigating the linguistic properties of the count/mass distinction, one can do so from two different perspectives. ${ }^{*}$ A first perspective focuses on the meaning of nouns. Whereas some nouns have a count meaning, others do not. Whereas a noun such as sandwich is count, and cannot easily obtain a mass interpretation, a noun like water is normally used with a mass interpretation. The second perspective considers the lexical or syntactic environment of a noun. In English, the use of a plural or an indefinite article will trigger a count interpretation of the noun, while a bare noun without plural marking cannot be a count noun. In this type of environment, a count noun such as sandwich will need to be reinterpreted as a noun with a mass meaning, otherwise the sentence is uninterpretable. Similarly, in a count environment, the mass noun water needs to obtain a count interpretation in order to be licit. Quantity expressions (two, a bit) play an important role in determining whether a context is count or mass. ${ }^{1}$

a. John ate sandwiches / a sandwich / two sandwiches.

b. \#John ate (a bit of) sandwich.

a. John drank (a bit of) water.

b. \#John drank waters / a water / two waters.

The count/mass distinction is a domain of language that is closely connected to cognitive notions such as individuation and number representation.

\footnotetext{
I would like to thank Hana Filip and two anonymous reviewers for their thoughtful comments on a previous version of this paper. For help with data, I would like to thank in particular Anikó Lipták, Simanique Moody, Yang Yang, Hang Cheng, Yiya Chen and Lisa Cheng. Yiya Chen also provided me with the tones for the Mandarin examples. Several parts of this research were presented during classes on the count/mass distinction in Leiden and in Curitiba (Brazil), at the Countability Workshop (Düsseldorf, 2013), the Conference on Referentiality (Curitiba, 2013) and the 11th International Symposium of Language, Logic and Cognition (Riga, 2015). I would like to thank the audiences for their input. Thanks also to Johan Rooryck for inspiring discussions on core knowledge systems. All the usual disclaimers apply.

${ }^{1}$ The following abbreviations are used: CL: classifier; EXP: experiential aspect; PRT: particle; PERF: perfective; PL: plural; PRS: present; SG: singular.
} 
Properties of the linguistic count/mass distinction may therefore shed light on the relation between language and cognition.

A question that is often asked in relation to the count/mass distinction is whether there are languages with or without a lexical count/mass distinction. What does it mean for a language to only have count nouns? Or only mass nouns? And what is the difference between count and mass nouns in the first place?

An example of a language that has been claimed to have only mass nouns is the numeral classifier language Mandarin. In numeral classifier languages, the syntax of nouns with typical count meanings (pen, apple, dog etc.) usually resembles the syntax for mass nouns, and numeral classifiers resemble measure words in a language such as English, as illustrated by the contrast between (3) and (4).

$\begin{array}{lllll}\text { a. } & \text { sān } & *(\text { gè }) & \text { píngguǒ } & \text { [Mandarin] } \\ \text { three } & \mathrm{CL}_{\text {gen }} & \text { apple } & \\ \text { b. } & \text { sān } & *(j \bar{n} n) & \text { mǐ } & \\ \text { three } & { }^{C L} \text { half_kilo } & \text { rice }\end{array}$

a. three apples

b. three $*($ kilos of $)$ rice

Based on these types of examples, one may want to conclude that all nouns in Mandarin are mass (see for instance Chierchia 1998a, 1998b, Denny 1986, Li 2013, Ojeda 1993; note that these authors have different perspectives on what it means for a noun to be mass).

On the other hand, in Yudja, all nouns combine directly with numerals, without number marking and without use of measure words or numeral classifiers (Lima 2010, 2014), leading Lima to the conclusion that in this language all nouns have count properties:
a. txabïu ali [Yudja]
three child
'three children'
b. txabüu y'a
three water
'three containers/drops/puddles etc. of water'

It is clear that in Mandarin, English and Yudja the types of strategies for combining numerals with nouns are different. However, what should be concluded on the basis of this in terms of the realization of the count/mass distinction in these languages? Do we want to assume that there are mass only (Mandarin), count only (Yudja) and count/mass languages (English)?

In this paper, I will approach these questions on the basis of cross-linguistic properties of quantity expressions. As indicated above, quantity expressions play an important role in creating count and mass environments across 
languages, as illustrated in in (1) and (2) above for English. In what follows, I will take the term quantity expression to cover expressions such as numerals, many, several and a lot, but also number markers, measure words and numeral classifiers. All these expressions are related to the expression of quantity, and their distributions influence each other within the language they occur in. I assume that quantity expressions in a particular language form a system in a Saussurian sense. Linguistic variation is due to the differences between the precise lexical inventory of different languages and the language-specific properties of these items.

However, quantity systems also show parallels cross-linguistically. In particular, I will argue that quantity expressions can be subdivided into expressions that presuppose countability and ones that do not. This distinction can be seen as a linguistic reflection of the cognitive distinction between number representation on the one hand (Dehaene 1997, Feigenson et al. 2004) and global quantity representation on the other (Lourenco and Longo 2011). The properties of these two types of expressions are tightly connected to the count/ mass distinction and make predictions on the possibilities of 'count only' and/ or 'mass only' languages; whereas a language in which nouns only have count meanings might exist (as count meanings are compatible with both basic types of quantity expressions), mass only languages are predicted to be impossible.

In Section 2.2, I will first introduce the notion of quantity system. After that, I will turn to parallels between quantity systems and I will defend the claim that there exists a fundamental linguistic distinction between count quantity expressions, which only combine with nouns that have count meaning, and global or non-count quantity expressions, which are indifferent with respect to the count/mass status of the meanings of the nouns they combine with (where I take a semantic approach to the count/mass status of nouns). Section 2.3 turns to the interaction between quantity expressions and count and mass meanings of nouns, focusing on the consequences of the existence of the two types of quantity expressions for the types of meanings we expect to occur crosslinguistically. Section 2.4 further investigates the interaction between quantity expressions and noun meaning, based on the idea that the presence of count quantity expressions may trigger an effect of "individuation boosting". Section 2.5 summarizes the main conclusions.

\subsection{Quantity Expressions across Languages}

\subsubsection{The Notion of "Quantity System"}

In what follows, I assume that quantity expressions in a given language form a type of system in a Saussurian sense of the term. Saussure (1916) compares the properties of a language system to those of a chess game in order to explain 
that certain properties of language are internal to the linguistic system, while others are not. Certain properties of a chess game are irrelevant for the system of chess, for instance, from which material the pieces are made, what their exact form is like and where the game originates. However, the number of pieces and the number of checkers, as well as the rules concerning the ways in which the pieces can or cannot move and other rules of the game, are part of the system. Changes in these domains will change "the grammar" of the game, as Saussure puts it (p. 44).

When looking at quantity expressions in a given language, one can observe that the conditions they impose interact with each other. Languages may have plural markers or not, and if a language has a plural marker, this marker will have language particular properties, which may affect the way other lexical items in the system function. For instance, in English, number marking is obligatory and interacts with the distribution of other quantity expressions as illustrated in in (1) and (2). Numerals such as two only combine with plural nouns. Nouns such as furniture, which have a countable meaning but which lack a singular-plural opposition, cannot combine with numerals (I will come back to this below).

Differences in lexical inventory seem to be at the basis of the large amount of variation in the count/mass distinction, including the three types of strategies illustrated in (3)-(5) for the ways in which nouns combine with numerals (classifier insertion, number marking and direct combination of the numeral and the noun) and many variants where a combination of these strategies is used (see Doetjes 2012 for examples). There is evidence that properties of individual lexical items play an important role in this variation. A nice example illustrating this is the distribution of classifiers in the Mayan language Chol (Bale and Coon 2014). Chol disposes of two sets of numerals, one of which requires the insertion of a classifier, while numerals of the other class directly combine with nouns, showing that the two types of numerals have different lexical properties and interact with classifiers.

Despite the differences that can be observed, quantity systems will be argued to have properties that encompass these differences and that I consider to be at the basis of the count/mass distinction. In the next sections, I will argue that quantity expressions (including classifiers, measure expressions and number markers) can be categorized in two basic classes, depending on whether they presuppose countability.

\subsubsection{Count, Non-Count and Anti-Count Quantity Expressions}

When looking at quantity expressions in English, a clear distinction can be made between three types of expressions: ones that only combine with count nouns, ones that combine with mass nouns and count plurals, and ones that 
only combine with mass nouns. Examples of the three types of expressions are given in (6):
a. John ate three apples/*soup.
b. John ate a lot of apples/soup.
c. John ate a bit of soup/*apples.

This results in the following classification of quantity expressions (cf. Chierchia 1998a):

A. expressions that presuppose the availability of units that can be counted (count quantity expressions);

B. expressions that do not presuppose the availability of units that can be counted (global quantity expressions or non-count quantity expressions);

C. expressions that presuppose the absence of units that can be counted ('anti-count' quantity expressions).

Below, I will present cross-linguistic evidence in favor of the idea that the first two types can be found across languages, independently of the strategy a language chooses for combining nouns and numerals. ${ }^{2}$ Moreover, I will argue that the third type ('anti-count') has a different status, and should be seen as a subclass of the non-count quantity expressions.

The basic distinction between expressions that presuppose the availability of units that can be counted and an evaluation of quantity in terms of number, and expressions that do not introduce such a presupposition is in my view related to the cognitive distinction between numerical magnitude representation and general magnitude representation (Doetjes 2017b). While the cognitive representation of numerical magnitude involves distinct, individuated units that can be counted (Dehaene 1997; Feigenson et al. 2004), general magnitude representations may depend on different measurement scales, such as weight and volume (Lourenco and Longo 2011). If this is right, the linguistic distinction between the two basic types of quantity expressions is rooted in a cognitive distinction. At the same time, language permits abstractions that make the linguistic distinction different from the cognitive distinction that is at the basis of it. I will come back to this at various points, and in particular in Section 2.3.3.

In the next section, the different types of quantity expressions will be illustrated on the basis of data from a number of unrelated languages. Before that, I will briefly go over their defining properties on the basis of English examples.

2 The distinction that I make between count and non-count quantity expressions is different from the difference between counting and measuring in Rothstein (2009, 2011). I will come back to this in Section 2.3.3. 
Count quantity expressions are defined by the property that they presuppose the availability of units that can be counted, which are normally provided by the noun they combine with, which must be compatible with a count interpretation. In a language like English, which has obligatory number marking, count quantity expressions combine with plural count nouns, and they are incompatible with mass nouns, unless a measure term is added:

$$
\text { three/several books/*(kilos of ) sand }
$$

Expressions such as three and several presuppose that the noun they combine with introduces units that can be counted and otherwise cannot be interpreted. ${ }^{3}$

Besides the numerals and vague expressions such as several, various and (how) many, several other quantity expressions presuppose countability of the noun they combine with. Examples are quantity expressions that include the word number (a number of) and distributive universal quantifiers (each, every). ${ }^{4}$ I also include the plural marker in this category, and I will argue below that the grammatical status of the plural marker has important effects on the ways in which quantity expressions in English interact with nouns and with each other.

Traditionally, the defining property of predicates that have a count denotation is atomicity (cf. Krifka 1992):

$$
\begin{aligned}
\text { a. } & \forall x, P[\operatorname{ATOM}(x, P) \leftrightarrow P(x) \& \neg \exists y[y<x \& P(y)]] \\
& (x \text { is a } P \text {-atom) } \\
\text { b. } & \forall P[\operatorname{ATM}(P) \leftrightarrow \forall x[P(x) \rightarrow \exists y[y \leq x \& \operatorname{ATOM}(y, P)]]] \\
& \text { (the predicate } P \text { has atomic reference) }
\end{aligned}
$$

According to Chierchia (1998a), all nouns have atomic reference. However, he also makes a distinction between atoms that are well-defined and atoms that are not, based on the concept of 'vague' atoms. Even though in his view a noun like water has atomic reference, these atoms are vague, and it is not clear what the atoms are. On the other hand, in the case of books, and also in the case of furniture, it is clear what the atoms are, namely the individual books and the individual pieces of furniture. In what follows I assume that a count denotation is an atomic denotation with non-vague atoms (see also Doetjes 1997; Deal 2017). ${ }^{5}$

3 The precise semantics of the various count quantity expressions will differ depending on the account that is adopted and is beyond the scope of this paper. Independently of the approach that is taken, their semantics will need to restrict them to an environment that provides units that can be counted.

4 Non-distributive universal quantifiers are usually indifferent with respect to the count/mass distinction. In the rest of this paper, I will not consider universal quantifiers, for reasons of space.

5 A known problem of atomicity is that some nouns that have clearly countable interpretations and that occur freely with numerals are not atomic (Nicolas 2004; Rothstein 2010b; Wiggins 1980; Zucchi and White 2001). Examples are twig, thing, fence and bunch. This problem is accounted for in the literature in various ways, such as context-dependency (Rothstein 2010b) and, within a mereological approach, a connectedness condition (Grimm 2012). 
The incompatibility of furniture and count quantity expressions will be related to the particular properties of plural marking in English.

Whereas some nouns are 'naturally atomic' in the sense that their primary denotation is count (e.g., bicycle), other nouns, often called 'notional mass nouns', typically have a mass meaning. However, this does not mean that they cannot have a count interpretation. Take, for instance, the examples in Yudja in (5), where the noun $y^{\prime} a$ ' water' is used to denote puddles or other 'individualized' portions of water. ${ }^{6}$ This is not possible in English, where three waters would rather refer to three types of water or three glasses of water in a restaurant. This illustrates the language-specific component in the availability of count meanings for notional mass nouns. The noun water has a denotation with vague atoms, while the atoms of the corresponding noun $y^{\prime} a$ in Yudja are not vague and correspond to contextually defined portions of water. ${ }^{7}$ What is similar across languages, however, is that count meaning plays a role in the linguistic system and interacts with quantity expressions.

I will also assume that measure words introduce countable units. Measure nouns such as kilo and liter also have a count, atomic denotation and behave as count nouns in many languages. If a numeral combines with kilos, the numeral counts the number of kilos, even if the boundaries between the kilos are usually arbitrary. One might argue that in this case the atoms are 'vague', but contrary to the vague atoms Chierchia discusses in the context of nouns such as water, the expression kilo makes clear what can count as an atom and what not, namely quantities that have a weight of one kilo. Similarly, in two kilos of sand we may not be able to distinguish two different objects, but still we know that the amount of sand we are talking about can be partitioned in two non-overlapping quantities of one kilo of sand. The assumption that measure nouns can have a count denotation has consequences for the mapping between language and cognition: kilos do not constitute discrete entities, and yet, in linguistic structures, they may be used as entities that we can count (see Section 2.3.3 below).

Contrary to count quantity expressions, global or non-count quantity expressions are compatible with nouns that have a count interpretation and with nouns that have a mass interpretation. As such, they do not presuppose countability. Examples of non-count quantity expressions in English are given in (9). In strict number marking languages such as English, these expressions typically combine with mass nouns and plurals:

more/less/a lot of books/sand

${ }^{6}$ Lima (2014, p. 118) assumes that the function that maps kinds to countable objects can apply to notional mass nouns because "the grammar of the language allows its speakers to treat concrete portions of a kind as atoms."

7 Note that this difference is not very relevant in the absence of quantity expressions. 
More, less and a lot in (9) are degree expressions. In languages such as English, these expressions usually cannot be used with a singular count noun, unless there is a shift to a mass meaning (an exception being no; no book(s)/sand): \#more/less/a lot of book

As argued by Link (1983), mass nouns and plurals are both characterized by cumulative reference, as defined in (11) (Krifka 1992):

$$
\forall P(C U M(P) \leftrightarrow \forall x, y[P(x) \& P(y) \rightarrow P(x \vee y)] \& \exists x, y[P(x) \& P(y) \& x \neq y]
$$

I assume that quantity expressions such as a lot are sensitive to cumulative reference only, which makes them compatible with mass nouns and count plurals. Note that it is not the case that expressions that indicate a degreerelated quantity need to fall in this category, as illustrated by English many, $a$ few and fewer. However, if a quantity expression with a degree-related meaning can also be used outside of the nominal system as a degree expression, it never presupposes that the noun it combines with has a count meaning (Doetjes 1997, p. 172); an expression such as fewer, which presupposes count meaning, cannot function as a degree modifier while less can (cf. *fewer/less complicated, to complain *fewer/less).

Measure words constitute another category of expressions that are often insensitive to the mass/count properties of the noun they modify, as illustrated in (12):

$$
\text { two pots/kilos of honey/olives }
$$

Even though the numeral two counts pots and kilos in this example, the quantity defined by the pots or kilos can be countable (olives) or non-countable (honey). Measure words do not always behave as non-count quantity expressions. Whereas most are compatible with plurals and mass nouns as illustrated in (12) (and thus constitute non-count quantity expressions), some are restricted to plurals (e.g., dozen) and others to mass nouns (e.g., drop). Measure words do not occur with singular count nouns, suggesting that they necessarily combine with expressions that have cumulative reference, irrespectively of the type of quantity expression they belong to. ${ }^{8}$

To conclude, in English non-count quantity expressions usually combine with mass nouns and plurals, that is, they combine with expressions that have cumulative reference without imposing further restrictions on these nouns. ${ }^{9}$

The third type of quantity expressions that I will consider are 'anti-count' quantity expressions. These expressions are very similar to the non-count

${ }^{8}$ Lehrer (1986) observes that measure words ('quantity related classifiers' in her terminology) differ in this respect from 'varietal classifiers' such as kind and type, as illustrated by a type of pen.

9 Most English quantity expressions, whether count or non-count, can also be used in partitive structures (a lot of these books). A discussion of partitives is beyond the scope of this paper. 
quantity expressions, but contrary to non-count quantity expressions they seem to be incompatible with count nouns altogether. An example is English a bit, as illustrated in (6c) above. If one wants to state that John read a small number of books, one has to use the count quantity expression a few, as in a few books. A similar distinction exists between much and many.

A possible way of accounting for anti-count quantity expressions is to assume that these expressions presuppose the absence of countability, and thus the lack of proper, identifiable atoms in the denotation of the nouns they combine with. This would mean that they could only combine with nouns that have divisive reference (Cheng 1973), the downward counterpart of cumulative reference, which implies the absence of atomic parts. ${ }^{10}$ Under this analysis, they would be the counterparts of count quantity expressions, as both types would introduce a presupposition related to the count/mass status of the nouns they may combine with. However, I would like to hypothesize that the restriction to mass environments has a different explanation, and that anti-count quantity expressions form a subclass of the non-count quantity expressions. The restrictions that are found are due not to selection, but to blocking.

In the literature, the distinction between many and much is often seen as an instance of blocking or the elsewhere condition (Di Sciullo and Williams 1987). Under a blocking account, much is not inherently incompatible with count nouns. However, the existence of many, which is incompatible with mass nouns and therefore more specific, blocks much from being used in a count context. In Doetjes (1997), I extended this analysis to the expression $a$ bit, which is replaced by the more restricted expression $a$ few in the context of a count noun. ${ }^{11}$ It is important to stress that the blocking effect must be due to a pairing of specific expressions in the lexicon. Whereas much gets replaced by many when the noun it combines with is a plural, this does not apply to a lot, which is compatible with both mass nouns and plurals, as illustrated in (9) above. $^{12}$

Despite the fact that it is hard to predict which elements get blocked and which do not, there are several arguments of treating expressions such as a bit as a special case of non-count expressions rather than as a separate subtype of expressions that presuppose divisivity (cf. also Chierchia 1998a).

10 See Deal (2017) for a definition of divisivity in line with the assumptions on count meaning in terms of non-vague atoms made above.

11 This could also be stated in terms of a general principle such as Maximize Presupposition (Heim 1991; Sauerland 2003).

12 There is evidence that this is a general property of blocking in the domain of quantity expressions. In French, the distribution of tant 'so much/many' is blocked by si 'so' in the context of adjectives ( $\mathrm{si} / *$ tant difficile 'so difficult'). However, tellement 'so (much/many)' is not blocked from this context (tellement difficile 'so difficult'). See Doetjes (1997, p. 112) for independent evidence for an analysis of these facts in terms of blocking. 
In the first place, the distribution of anti-count expressions is very similar to the one of non-count quantity expressions such as more. Both a bit and more are found not only in the context of nouns, but also in the context of verbs, and they can even be used with adjectives, in which case they indicate a degree rather than a quantity (cf. Doetjes 1997, 2008): a bit/more complicated/to complain a bit/more.

In the second place, when the expression a bit is modified, it may lose the property of being restricted to mass expressions. In particular, modification by quite facilitates, for some speakers at least, the use of a plural noun, as in \% quite a bit of books.

In the third place, research on the acquisition of many and much follows the pattern that is expected under a blocking analysis. Gathercole (1985) shows that children first use much with both count and mass nouns, that is, they use it as if it were a non-count rather than an anti-count expression. Moreover, they start to use it correctly only when they have acquired a correct use of many, which is acquired later than much. This is very similar to the pattern described by Ferdinand (1996) for the acquisition of the verbal paradigm of agreement morphology in French and to the pattern Pinker (1995) describes for the acquisition of irregular verb forms in English, two phenomena for which a blocking type of analysis is commonly assumed.

To conclude, there seems to be an asymmetry between count quantity expressions and anti-count quantity expressions. Anti-count expressions do not behave as counterparts of count quantity expressions, but rather seem to be a subcase of non-count quantity expressions. This asymmetry can be accounted for by the hypothesis that the distribution of anti-count quantity expressions is due to a blocking effect, which is triggered by the existence of an equivalent count quantity expression with which it is strongly associated. The special status of anti-count quantity expressions may be a reason why they are cross-linguistically rare compared to the two other types (Chierchia 1998a).

In the following sections, I will discuss examples of count, non-count and anti-count quantity expressions in several languages. After this, I will turn back to the notion of quantity systems. ${ }^{13}$

\subsubsection{Count Quantity Expressions across Languages}

Numerals are count quantity expressions by definition, as their meaning presupposes the availability of units that can be counted. If a language has

13 Note that I will restrict myself to languages in which quantity expressions form part of a noun phrase. This is clearly not always the case cross-linguistically (see Bach et al. 2013). I expect that the basic semantic distinction between count and non-count quantity expressions also applies to quantity expressions with a different type of syntax/semantics (see Wilhelm 2008 for data that point in this direction). 
numerals, this implies that it has expressions that can only combine with nouns that have a count meaning. As shown in the discussion above, the ways in which numerals interact with nouns vary across languages. What is constant, however, is the type of meaning they require, which needs to be countable. Not all languages have a fully developed system of cardinal numerals (cf. for instance Wiese 2003), but it is quite plausible that all languages have quantity expressions that presuppose countability. Even languages that have very restrictive numeral systems - e.g., Mundurucu (Pica et al. 2004) - seem to have quantity expressions that resemble numerals or expressions such as several in the sense that they presuppose the availability of units that can be counted.

Next to numerals, languages often also have expressions that presuppose countability that do not indicate a precise number. English examples are several, various, different, (a) few and many, and the existence of this type of quantity expression turns out not to be restricted to languages with obligatory plural marking in the context of numerals.

A first example is the numeral classifier language Mandarin. In Mandarin, vague quantity expressions may have a distribution that is similar to that of numerals, including $j \check{l}$ 'how many, a few'. These expressions are usually assumed to occupy the same structural position as numerals (see for instance Hsieh 2008, p. 62; Zhang 2013, p. 85). On a par with numerals, these expressions obligatorily trigger the insertion of a classifier when combined with a noun, and as such they are restricted to count environments; this is illustrated by the examples in (13) (see Zhang 2012, p. 43). I will turn to classifiers and their relation to the meaning of the noun below. ${ }^{14}$

$$
\begin{aligned}
& \text { a. Nǐ yǒu jǐ } \quad * \text { (duǒ) huā? [Mandarin] } \\
& \text { you have how.many CL flower } \\
& \text { 'How many flowers do you have?' } \\
& \text { b. Yīgòng yǒu jĭ *(shēng) yoú? } \\
& \text { total have how.many } \mathrm{CL}^{\text {liter }} \text { oil } \\
& \text { 'How many liters of oil are there in total?' }
\end{aligned}
$$

A perhaps more surprising example of a quantity expression that presupposes countability is the expression dàduōshù 'most' (lit. 'bigger number'). This quantity expression directly modifies the noun. It is optionally followed by the marker $d e$, which marks nominal modifiers, and cannot be combined with a classifier. According to Zhang (2013, p. 139), it is incompatible with mass nouns such as mò-shǔ 'ink', a property that can be traced back to the presence of the morpheme shù 'number' (for some speakers I consulted, this restriction does not hold; I leave this as an issue for further research):

14 Example (13a) is also given in Zhang (2013, p. 86); example (13b) has been slightly adapted. 

a. dàduōshù shū diào-dào dì-shàng le. [Mandarin] Most book fall-to ground-on PRT
'Most of the books fell on the ground.'
b. *dàduōshù mò-shuǐ liú-dào dì-shàng le. most ink-water flow-to ground-on PRT 'Most of the ink flew to the ground.'

Turning now to a typologically different language, again we can find expressions that are restricted to count environments. Hungarian hány 'how many' (Schvarcz and Rothstein 2017) is in this respect similar to Mandarin ǰ̌ 'some, how many' and English how many, even though the strategy that is used to combine the quantity expression and the noun differs. In Hungarian, number marking is obligatory in definite noun phrases but absent in the context of numerals and other quantity expressions, which I take to be an indication of the number-neutral nature of these nouns (Farkas and de Swart 2010). ${ }^{15}$ An example illustrating the distribution of hány 'how many' is given in in (15): ${ }^{16}$
a. Hány könyv áll a polcon? [Hungarian] how.many book stand.3sg the shelf.on
'How many books are on the shelf?'
b. *Hány por áll a polcon? how.many dust stand.3sg the shelf.on

The impossibility of combining hány with notional mass nouns shows that Hungarian differs from Yudja. The strategy of directly combining nouns and quantity expressions does not imply the freedom of count meanings available in Yudja (cf. Wilhelm 2008).

Next to the quantity expressions discussed above, number markers and certain classifiers are themselves also count quantity expressions, as they presuppose a count interpretation of the noun they combine with.

Let us first turn to count selecting classifiers. There are two types of classifiers that are only compatible with nouns that have a count interpretation, and thus can be said to presuppose countability: sortal classifiers and group classifiers. An example of a sortal classifier in Mandarin is given in (16):

$$
\begin{array}{llll}
\text { sān } & \text { zhī } & \text { bǐ } & \text { [Mandarin] } \\
\text { three } & \mathrm{CL}^{\text {branch }} & \text { pen } & \\
\text { 'three pens' } & & &
\end{array}
$$

It has been argued in the literature that sortal classifiers introduce count meaning and that in the absence of the classifier the noun is semantically mass (see for instance Denny 1986; Ojeda 1993). However, if this is taken in a literal

\footnotetext{
15 Hungarian disposes of one sortal classifier, which is optionally inserted with numerals and count quantity expressions, see Schvarcz and Rothstein (2017).

16 I would like to thank Anikó Lipták for providing these examples.
} 
sense, count meaning should be only available in the context of classifiers. This is not the case, as bare nouns may have count meanings in the absence of a classifier. Moreover, nouns that are compatible with sortal classifiers always can have a count, atomic interpretation in the absence of the classifier (see also (14) and (17)). Nowadays, it is commonly assumed that nouns that are compatible with sortal classifier need to have a count meaning independently of the presence of the classifier (Chao 1968; Cheng and Sybesma 1998, 1999, 2005; Doetjes 1997, 2012, 2017c; Grinevald 2005; Li et al. 2009; Zhang 2013).

Besides sortal classifiers, group or plural classifiers also presuppose the presence of units that can be counted in the denotation of the noun they combine with. Consider for instance the examples in (17) (Doetjes 1997, p. 34):

$$
\begin{array}{lll}
\text { ȳi } \quad \text { dá/qún } & \text { bái-mǎ } & \text { [Mandarin] } \\
\text { one } \quad \mathrm{CL}^{\text {dozen/herd }} & \begin{array}{l}
\text { white horse } \\
\text { 'a dozen/herd (of) }
\end{array} \text { white horses' }
\end{array}
$$

Contrary to numerals, these expressions are incompatible with sortal classifiers. As in the case of sortal classifiers, group classifiers are incompatible with nouns that have a mass interpretation.

A final class of expressions that presuppose the existence of units that can be counted is the class of number markers. Number markers show up in very different ways across languages. English number marking is obligatory and plays a role in the selection properties of numerals, and English is often seen as the prototypical case of a number marking language. ${ }^{17}$ As in the case of classifiers, number markers show a large amount of cross-linguistic variation (see, among many others, Cabredo Hofherr forthcoming; Corbett 2000; Dryer 2005; Wiltschko 2008). Both classifiers and number markers seem to be freer in the types of restrictions that they may impose on the expressions they combine with. Besides presupposing count meaning, number markers may also be sensitive to animacy, for instance. In numeral classifier languages, it is usually the case that different nouns combine with different sortal classifiers.

To sum up, count quantity expressions are commonly found across languages (in particular numerals, expressions such as several and how many,

17 It is actually not clear how frequent the English type of system is. WALS classifies 133 languages out of a sample of 291 as languages that have always-obligatory number marking on all (count) nouns. However, among these 133 languages many are very different from English. The Austronesian numeral classifier language Mokilese, for instance, falls in this class. In this language number marking on determiners and demonstratives is (mostly) obligatory, but there is no number marking on nouns (Harrison and Albert 1976). In a different vein, the distribution of number markers in languages with obligatory number marking on nouns is not always the same as in English (see for instance Hungarian; Farkas and de Swart 2010). 
sortal classifiers and plural markers). Languages differ in the number and types they make use of and the ways in which they interact with each other, but the general property of being sensitive to the availability of count meaning may well be a basic classificatory property of quantity expressions across languages. In Section 2.2.5 I will turn back to the interaction between quantity expressions, but before that I will first discuss cross-linguistic occurrences of non-count and anti-count quantity expressions.

\subsubsection{Non-Count and Anti-Count Quantity Expressions across Languages}

The core property of non-count quantity expressions is that they presuppose neither the availability of units that can be counted nor the absence thereof. Again, it seems plausible that expressions that belong to this type are crosslinguistically widespread or even universal.

Degree-related quantity expressions often do not presuppose the availability of units to count or the absence thereof. Examples for English are given in (9), repeated in (18):

$$
\text { more/less/a lot of books/sand }
$$

As indicated above, expressions of this type in English are claimed to be sensitive to cumulative reference of the expression they combine with. In the context of this type of quantity expression, the presence or absence of a count interpretation depends on the meaning of the noun (see in particular Barner and Snedeker 2005). The conditions on the use of degree expressions depend partly on the distribution and function of numeral classifiers and number marking in a language. In English, where marking of plural is obligatory and where the singular form is usually assumed to have a singular meaning (see for instance Chierchia 1998a, Link 1983), these expressions typically combine with plural count nouns and with mass nouns while being incompatible with count singulars.

Deal (2017) claims that the Sahaptian language Nez Perce exhibits a similar pattern for a large class of quantity expressions. At first sight, Nez Perce is very different from English. All nouns in Nez Perce are permitted to be used in count contexts, as in Yudja, and it seems as if all quantity expressions freely combine with all nouns. However, Deal convincingly argues that this view is too simple. Whereas numerals always trigger a count interpretation of the noun, other quantity expressions do not. Moreover, when notional count nouns are used, plural marking on the noun (for human nouns) and/or on the adjective (in other cases) is obligatory in the context of a count interpretation, as illustrated for the quantity expression 'ilex̂ni 'a lot' in (19) (Deal 2017, pp. 149-150): 

a. 'ilex̂ni ha-ham/*haama
[Nez Perce]
a.lot PL-man/*man.SG
'a lot of men'
b. 'ilex̂ni ??tiyaaw'ic/ ti-tiyaw'ic wix̂si'likeecet'es
a.lot ??sturdy/ PL-sturdy chair
'a lot of sturdy chairs'

With notional mass nouns, the presence versus the absence of a plural marker corresponds to the presence versus the absence of a count interpretation of the noun (Deal 2017, p. 152):
a. 'ilex̂ni cimuuxcimux
samq'ayn
[Nez Perce]
a.lot black
fabric
'a lot of black fabric'
b. 'ilex̂ni cicmuxcicmux samq'ayn
a.lot PL.black fabric
'a lot of pieces of black fabric'

The resulting pattern is strikingly similar to the one illustrated in (9) and (10) for English: even though the number markers are realized in a different way, plural marking is obligatory in the context of nouns with a count meaning. Deal, who also assumes that quantity expressions such as 'ilex̂ni 'a lot' are sensitive to cumulative reference, takes this to be an argument in favor of the idea that there is a singular-plural opposition in Nez Perce that is very similar to the one that is commonly assumed for English: whereas plural marked nouns with a count meaning have cumulative reference, the corresponding singular nouns denote sets of atoms, and are quantized. Under the assumption that quantity expressions such as 'ilêxni 'a lot' only combine with expressions that have cumulative reference, it follows that nouns with a count interpretation need to be pluralized in this context.

As already indicated above, many languages do not require plural marking or classifier insertion in the context of numerals, even though some of these languages have obligatory plural markers in other contexts. Examples are Yudja and Hungarian. For Hungarian, which clearly allows for mass meanings, non-count expressions can be easily found. Whereas the Hungarian quantity expression hány 'how many' in (15) above is only compatible with nouns that have a count interpretation, sok 'a lot' and mennyi 'how many/much' are insensitive to the count/mass status of the noun they combine with; (21a) is from Farkas and de Swart (2010, p. 11) and (21b-d) from Anikó Lipták (p.c.).
a. Sok gyerek gyült össze a téren. [Hungarian] a-lot child gather.PAST PRT the square.on 'Many children gathered in the square.'
b. Sok sár gyült össze a téren.
a-lot mud gather.PAST PRT the square.on
'A lot of mud accumulated on the square'


c. Mennyi könyv áll a polcon? how.many book stand.3SG the shelf.on 'How many books are on the shelf?'

d. Mennyi por áll a polcon? how.much dust stand.3sG the shelf.on 'How much dust is on the shelf?'

For a language such as Yudja, it is harder to show that a distinction between count and non-count quantity expressions exists, given that count quantity expressions combine so easily with notional mass nouns. However, Lima (2014) shows that not all quantity expressions behave in the same way in quantity judgment tasks. More in particular, itxïbi 'many' requires an evaluation in terms of number, while bitu 'more' also permits an evaluation in terms of volume. This suggests that itxïbï is a count quantity expression, while bitu is non-count and as such similar to English more (see also Section 2.3.1).

In classifier languages as well, it is possible to find non-count quantity expressions. These are compatible with all nouns, independently of the type of meaning they have and can be assumed to be sensitive to cumulative reference, under the assumption that the noun has a number-neutral interpretation (Cheng and Sybesma 1999, Rullmann and You 2006). In general, noncount quantity expressions can come in two types, depending on the possibility of inserting a classifier. An example of is hěnduō, which is insensitive to the count/mass status of the noun it combines with, as illustrated in the examples in (22) (Zhang 2013, p. 19): ${ }^{18}$
a. Wǒ yǐqían mǎi-guò hěnduō máo-pǐ, [Mandarin]
$1 \mathrm{sG}$
xiànzài
before buy-EXP
a.lot
brush-pen
now
liăoliăowújǐ.
few
'I bought many brush-pens before, but few of them remain now.'
b. Wǒ yǐqían mǎi-guò hěnduō mò-shuǐ,
1SG before buy-EXP a.lot ink-water
*xiànzài shèngxìa liăoliăowújín.
now remain few
'I bought much ink before, *but few of them remain now.'

Depending on the dialect, Mandarin hěndū̄ may be followed by a classifier (Cheng et al. 2012; Doetjes 2012), but this is never necessary (see also Section 2.3.4 below). Other non-count quantity expressions never permit insertion of a classifier. These expressions function as modifiers and may be followed by $d e$,

18 In the original gloss, hěnduō is translated as many. Given that hěnduō is a non-count quantity expression, I changed this into 'a.lot'. 
a marker of nominal modification. As in the case of hénduō, the noun can be either count or mass (Hsieh 2008). Examples are dàliàng 'a lot', suǒyǒu 'all', quánbù 'all', and dàbùfèn 'most' (Zhang 2013, p. 84): ${ }^{19}$
a. dàliàng
(de) $(*$ duō)
huā
a.lot
(de) $\left({ }^{*} \mathrm{CL}\right)$ flower
[Mandarin]
'a lot of flowers'
b. dàliàng (de) (*píng) shuǐ
a.lot (de) $\left.*^{*} \mathrm{CL}^{\text {bottle }}\right)$ water
'a lot of water'

Mensural classifiers (in classifier languages) and measure words (in non-classifier languages) are often indifferent to the count/mass status of the nouns they combine with. This is illustrated in (12) above for English and in (24) for Mandarin:
a. liăng jīn mǐ/ píngguǒ [Mandarin] two $\mathrm{CL}^{\text {half_kilo }}$ rice/ apple 'two pounds of rice/apples'
b. liăng píng (de) mì/ gănlăn two $\mathrm{CL}^{\text {pot }}$ (DE) honey/ olive 'two pots of honey/olives'

Measure constructions and measure terms are not found in all languages (see for instance Lima 2014, p. 22, who states that they are absent in Yudja). In classifier languages, measure words usually surface as classifiers, but not necessarily (Doetjes 2017a). As indicated in Section 2.2.2 above, measure words (whether classifiers or not) typically combine with nouns that have cumulative reference.

Next to quantity expressions that are indifferent to the count/mass distinction, there are also quantity expressions that are incompatible with nouns that have a count interpretation, as illustrated by English much and $a$ bit. These expressions, which I called anti-count quantity expressions above, typically combine with mass nouns. As indicated in the previous section, I assume that anti-count quantity expressions should be considered to be a special case of non-count degree expressions and that some kind of blocking process plays a role in limiting the distribution of these expressions to mass contexts.

As in the case of the other types of expressions discussed above, anti-count expressions can be found in typologically different languages. Pairs like a bit and $a$ few, describing small quantities, seem to be cross-linguistically quite common, even though there also exist languages where a single expression is

19 The semantics of these expressions is often transparent: dà 'big' + liàng 'quantity', quán 'complete' + bù 'part' and dà 'big' + bù 'part' + fèn 'fragment' (Yang Yang, p.c.). 
used (e.g., Breton un nebeud 'a few, a bit', Hamon 1984). ${ }^{20}$ In Mandarin, $y \bar{\imath}$ diănr belongs to the class of expressions that combine typically with nouns that have a mass interpretation (Iljic 1994). In case a count meaning is present, the expression $j \check{\imath}$ ' a few' is used, which triggers the obligatory insertion of a classifier. $^{21}$

Some measure words are also restricted to mass nouns. In general, they impose more restrictions on the noun they combine with. Take, for instance, the example drop or liter. A drop/liter of $N$ can only be used if $\mathrm{N}$ denotes a liquid, and as liquids are mass nouns in English, the expression is restricted to mass nouns as well. ${ }^{22}$ In this respect, the nature of the restriction seems different from the restriction we find for $a$ bit or $y \bar{\imath}$ diănr, of which I argued that they are in principle compatible with count expressions, but blocked in this context by the existence of a more specific expression that presupposes the existence of units to count.

\subsubsection{Back to Quantity Systems}

In the preceding sections, I introduced a distinction between count and noncount quantity expressions and argued that this distinction exists crosslinguistically. As indicated, cross-linguistic variation comes from the actual inventory of quantity expressions, which I assume to form systems in a Saussurian sense.

Number markers and classifiers are an important source of cross-linguistic variation, as they may have different distributions in different languages. The fact that English has a grammatical and obligatory singular-plural opposition affects the way quantity expressions interact with each other and with nouns.

20 The fact that anti-count expressions often indicate a small quantity might be related to the fact that there is a separate system of numerical recognition for small quantity (see for instance Feigenson et al. 2004). I leave this as a question for further research.

21 Zhang (2013, p. 88) challenges the claim that $y \bar{\imath}$ diănr 'some, a bit' is an anti-count quantity expression on the basis of the example in (i). According to her judgments, it is possible to use it in the sense of $a$ few with nouns that have a count interpretation (the use of a classifier being still prohibited):

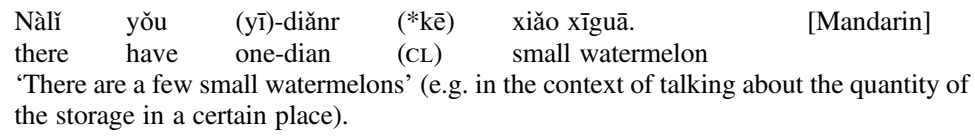

The reactions of the Mandarin speakers I consulted suggest that judgements vary: some only could get the reading corresponding to 'a bit of small watermelon' (in which case, xiao xigua 'small watermelon' is necessarily interpreted as a type of watermelon), while others could also get the reading 'a few small watermelons'.

22 The same could actually be said about many group classifiers: the term flock can only be used in the context of certain types of animals. 
Count quantity expressions in English are also sensitive to the presence of plural marker. In this respect, English plural markers interact with the selection properties of other count quantity expressions. At the same time, in systems with obligatory plural marking, exceptions to number marking may arise (Chierchia 2010; Doetjes 2010), as exemplified by nouns such as furniture. ${ }^{23}$ Nouns such as furniture are not compatible with numerals and expressions such as many or numerals, despite their count meaning. ${ }^{24}$

A different example of how language-specific properties of quantity expressions may interact comes from Mandarin. Numeral classifiers are systematically used with numerals and a small set of other quantity expressions. As shown above, expressions such as dàbùfèn 'most' occur in a modifier position and are incompatible with classifiers. Given that the measure words in measure constructions are always realized as classifiers in Mandarin, they are incompatible with expressions such as dàbùfèn 'most', so that most bottles of water cannot be translated as in $(25):{ }^{25}$

$$
\begin{array}{llll}
\text { dàbùfèn } & \left({ }^{*} \text { píng }\right) & \text { shuǐ } & \text { [Mandarin] } \\
\text { most }\left({ }^{*} \mathrm{CL}{ }^{\text {bottle }}\right) & \text { water }
\end{array}
$$

This section focused on cross-linguistic properties of quantity expressions. In the next two sections, I will first turn to the consequences of the available types of quantity expressions for the types of noun meanings that need to be available cross-linguistically (Section 2.3). Then I will consider cases where noun meaning interacts with the presence vs. absence of count quantity expressions (Section 2.4).

\subsection{Count and Mass in the Lexicon: Properties of Nouns}

\subsubsection{Mass and/or Count Only Languages?}

If it is correct that quantity expressions that presuppose countability are universal, count meaning must be strongly anchored in the nominal system across languages, which is in accordance with the importance of counting and

23 Pluralia tantum such as oats are also exceptions to the general rule. In the context of these nouns, most count quantity expressions are simply excluded, as they are uninterpretable in the context of mass meaning. However, people hesitate between much and many, the normative rule being that many is required because of the plural marking.

24 The reason for this could be semantic (see, for instance, Bale and Barner 2009; Rothstein 2010b) but also morphological (see Cowper and Hall 2012).

25 With some of the expressions that do not require classifier insertion, some speakers allow for the use of (mensural) classifiers, while other speakers apply stricter rules and do not permit the use of a classifier. If the mensural classifier is prohibited, a literal translation of e.g., most bottles of water is not available. See Rothstein (2010a) for a similar phenomenon in Hebrew. 
individuation in cognition (see for instance Spelke and Kinzler 2007). The cross-linguistic availability of these expressions predicts that all languages should have nouns that have or at least can have a count meaning. It is important to realize that this also applies to classifier languages: classifiers do not create a system in which all nouns have mass meaning, given that sortal classifiers can be shown to presuppose countability themselves. This means that 'mass only' languages cannot exist.

Non-count quantity expressions do not require either count or mass meaning, and as such do not predict anything with respect to the types of noun meanings that need to be available. If selection on the basis of mass meanings does not exist, as I argued in the previous section, languages could in principle do without mass meaning. An obvious candidate for a language without mass meaning is course Yudja, as illustrated by the examples in (5) above. According to Lima, notional mass nouns in Yudja have an atomic, count meaning, which is similar to the count meaning that notional count nouns have, and she offers conclusive evidence for the possibility of interpreting notional mass nouns as count. However, one may also wonder whether Yudja offers any evidence for the possibility of a mass meaning for notional mass nouns such as $y$ ' $a$ 'water'.

According to Deal (2017), who argues that count only languages are not possible (cf. the Nez Perce data in (19) and (20) above), such evidence exists. Her claim is based on the results of a specific quantity judgment task with bitu 'more', in which no choice was offered in terms of number (Lima 2014). ${ }^{26}$ Out of twenty adult Yudja speakers surveyed, 88 percent interpreted (26) in terms of volume and opted for the big pile of flour in the given context (Lima 2014, p. 132):

Context: there is one large pile of flour and one small pile of flour.

Ma de bitu asa dju a'u? [Yudja] who more flour have

'Who has more flour?'

According to Deal, the fact that the volume reading was permitted and even preferred indicates that the noun asa 'flower' can have a mass reading. However, this is not a necessary conclusion. As Lima indicates, bitu 'more' does not force a count interpretation in the same way as itxib $\ddot{i}$ 'many' does, as shown by the results of her standard quantity judgment tests (in which both number and volume vary). If the results of the test with bitu 'more' are compared to the ones with itxib̈̈ 'many', an interesting difference shows up.

26 In the standard quantity judgment task, one picture represents the largest volume and the other the largest number, e.g., one large pile of flour and three small ones (cf. Barner and Snedeker 2005). 
Whereas quantity judgments for itxïbï 'many' yielded a 100 percent score with all nouns for adults (Lima 2014, p. 187), the results with bitu 'more' showed more variety: in about 15-20 percent of cases, the adults would make an estimation based on volume rather than on the number of portions (p. 122). This suggests that itxib $\ddot{i}$ 'many' is a count quantity expression, while bitu 'more' is a non-count quantity expression and as such is compatible with a global quantity meaning. The question is then whether the volume reading is possible if the noun has a count interpretation.

For Deal, the answer to this question seems to be no. The distinction between an evaluation based on number and one based on global quantity is claimed to be due to the count or mass meaning of the noun, and as such the absence of an evaluation in terms of number implies mass meaning. Under this assumption, the results of Lima's experiments show that there is only a preference for the count meaning of notional mass nouns in Yudja.

However, there is also another way to interpret the data. One could assume that bitu 'more', being a non-count expression, does not imply that the evaluation is made in terms of number, even if the noun has a count interpretation. Whereas an evaluation in terms of number is strongly favored in the context of a noun with a count meaning (see also the original experiments of Barner and Snedeker 2005), there is no a priori reason to assume that an evaluation in terms of volume would be excluded (see also Section 2.4). In Lima's experiments with bitu, evaluation in terms of number is preferred for all nouns, but this is so independently of whether the noun is notional mass or notional count. Evaluation in terms of volume is also attested, contrary to what is found for the quantity judgment experiments with itxïbi 'many'. This shows that this option is independent of the presence of a mass (that is, divisive) meaning, as it is unlikely that the effect in the examples with notional count nouns is due to a count-to-mass meaning shift. In the example in (26), an evaluation in terms of volume is the only option, as a comparison in terms of number is excluded. This explains the high percentage of answers based on an evaluation in terms of volume. The interpretation of (26) is thus not a sufficient reason to conclude that notional mass nouns in Yudja also can have a mass meaning.

Other data that may suggest that nouns in Yudja can have a mass meaning are not conclusive either. First, Lima (2012) reports that the nouns kapiiia 'fog' and makasu 'wind' are incompatible with modifiers such as itxïb̈ 'many', and assumes that "individualization of portions is not possible." This does not exclude however, that they are conceived of as nouns with a unique referent (cf. the sun). Second, the quantity expression xinaku 'a little' seems to behave as an anti-count quantity expression. Contrary to urahu 'big', this expression cannot be used to modify notional count nouns (Lima 2012, example (44)): 

a. xinaku/urahu apeta [Yudja] a little/ big blood
'(There is) a small/big amount of blood in a single place'
b. \#xinaku ali
a little child
c. urahu ali
big child
'(There is) a big child'

The properties exemplified by urahu 'big' are also found in other languages in which notional mass nouns such as blood are easily used as count nouns, such as Nez Perce (Deal 2017). As also indicated by Lima and Dahl, if urahu means 'big' in the context of a notional count noun, the interpretation in (27a) is expected under a count interpretation of the noun apeta 'blood'. The impossibility of (27b) shows that the same reasoning does not apply to xinaku. However, Lima's translation still suggests that the blood is in a single space, and more evidence seems necessary in order to conclude that xinaku is only compatible with apeta under a mass interpretation of the noun. This means that Yudja still seems to be a candidate of a language in which all nouns have a count meaning.

Based on the asymmetric properties of quantity expressions with respect to count meaning, languages are predicted to have either both count and mass meanings for nouns or only count meanings. This excludes the possibility of 'mass only' languages, while 'count only' languages may well exist. This is in accordance with the observation that Yudja is a serious candidate of a count only language. In the next subsection I will turn to the types of count meanings that are available cross-linguistically, and the large amount of variation in this domain.

\subsubsection{Available Count Meanings and Cross-Linguistic Variation}

The examples of Yudja and Nez Perce are also important from the point of view of linguistic variation in terms of the types of meanings that nouns may or may not have. The types of count meanings that are allowed in these languages are not available in all languages and cannot be directly translated into English. The grammatical properties of Nez Perce laid out in Deal show, moreover, that the free availability of count meanings for notional mass nouns is possible in a grammatical system that shows a strong resemblance to English (see (19) and (20) above). In general, there is a large amount of variation in the types of count and mass meanings nouns may or may not get, and this is to a large extent arbitrary. The English word for bacon cannot mean 'slice of bacon', while the Blackfoot word for bacon can (Franz and Russell 1995, cited in Wiltschko 2012): 


$$
\begin{array}{lll}
\text { singular } & \text { plural } & \\
\text { aiksinoosak } & \text { aiksinoosakiksi } & \text { [Blackfoot] } \\
\text { 'bacon' } & \text { 'bacon' (slabs or slices of }) &
\end{array}
$$

Similarly, Cheng et al. (2008) show that English and Dutch differ from Mandarin Chinese and Gungbe (a Kwa language spoken in Benin) in terms of the possibilities they offer for assigning a mass meaning to a typical count noun (e.g., dog). Similarly, the use of a typical mass noun with a count type reading, as in two different golds for two types of gold, is much more limited in Dutch than in English (Doetjes 1997) (*twee gouden 'two golds' is impossible under the intended reading) and has been claimed to be absent in Ojibwe (Algonquian, Mathieu 2012).

Differences between the lexical choices languages make with respect to noun meaning can also be illustrated by the well-known contrast between the word advice in English and its French translation conseil. Whereas French conseil is used in combination with quantity expressions that presuppose countability (plusieurs conseils 'several pieces of advice'), English advice can only be used in contexts that do not presuppose countability (more/less advice $\left.\left({ }^{*}\right)\right)$. Similarly, success in English is a mass noun, while failure is a count noun. It turns out to be extremely hard to predict the count or mass properties of nouns, especially in the domain of abstract nouns (Gillon 2012, Grimm 2014, Pelletier and Schubert 1989). ${ }^{27}$

These examples illustrate that available meanings vary cross-linguistically, which implies that there is an important language-specific lexical component involved. Even in flexible meaning approaches (Bale and Barner 2009; Borer 2005; Pelletier 2012), where nouns have one flexible meaning which is compatible with both mass and count grammatical contexts, it will not be possible to do without a lexical component delimiting the possible interpretations of a noun (whatever theoretical status these interpretations have) in a given language. Given the scarce systematic cross-linguistic literature on this topic, more research is necessary.

\subsubsection{Count Meaning, "Default Units of Counting" and Abstraction}

The acquisition of the count/mass distinction illustrates the way language makes more abstract count meanings available. As pointed out by Brooks et al. (2011), children who acquire the count/mass distinction first strongly rely on the "default units" of counting that are pre-linguistically available (see also

27 The difference between conseil and advice is similar to the difference between French rougir, which is an accomplishment verb, and its Dutch and English translations blozen and to blush, which are activity verbs. The phenomenon these verbs describe can be conceived of as an accomplishment and as an activity. 
Shipley and Shepperson 1990). These units correspond to cognitively salient units, such as physical objects and sounds. During the first stages of acquiring count meaning, counting depends on these default units. Take, for instance, a context where there are three forks and two half forks - that is, one fork that has been broken in two pieces - so that there are five separate physical objects and four forks. In this context, young children who are asked to count the number of forks will tend to count the number of objects instead, while older children and adults will abstract away from the fact that one fork is made up of two half forks. This is an important observation in view of the difference between language and cognition: even though cognition makes us sensitive to counting and default units, language allows us to define new units and to count these instead of the "default units of counting."

In what preceded, I assumed that measure words such as kilo are count nouns and have count meaning. Evidence for this is that they behave like ordinary count nouns: they can be combined with numerals, and if they are, they are marked for number. If this assumption is correct, languages allow for highly abstract count interpretations.

This view is different from the one presented by Rothstein (2009, 2011, 2017). Rothstein makes a distinction between measuring and counting based on the two types of readings one can get for expressions such as three bottles/ liters of wine. On the one hand, the measuring expression three bottles/liters can define, or measure, a quantity of wine, resulting in a reading where we talk about a certain quantity of wine, as in they drank three bottles/liters of wine last night. This is the most natural reading for expressions such as kilo or liter. Alternatively, three bottles/liters of wine can denote three actual (liter) bottles filled with wine, as in she put three bottles/liters of wine on the table. In this case, the numeral counts actual bottles of wine. ${ }^{28}$ Rothstein reserves the term counting to this second use. From the perspective of the current paper, numerals are always count quantity expressions and as such they are interpreted in relation to units that can be counted. In Rothstein's "measuring" cases, these units are abstract, and in the "counting" contexts, the units are concrete, but in both cases I assume that the numeral has a similar meaning and counts the units. My aim is to make a classification of quantity expressions based on their general distributional properties. In this respect, it is important to realize that not only numerals (which are selected by the measure word in Rothstein's account), but also other count quantity expressions in English combine with measure words under their abstract reading, as illustrated by the examples in (29).

28 Rothstein argues that this meaning difference involves also a structural difference. Whereas [[three bottles] of wine], in which the word bottle first combines with the numeral, corresponds to measuring, the structure [three [bottles of wine]], corresponds to a reading with three individual bottles. 
a. Every inch of cloth is used, nothing is wasted.

b. If you want to make that dress, you will need several yards of fabric.

Neither of these examples assumes that the cloth or fabric is cut into inches/ yards, which shows that they cannot be treated as cases of "counting" in Rothstein's terms. This shows that the abstract meanings are available irrespectively of the type of count quantity expression (numeral or other).

\subsubsection{Properties of Nouns: Summary}

The idea that there is a fundamental distinction between quantity expressions that presuppose the existence of units to count and quantity expressions that do not make this presupposition has consequences for the type of noun meanings that we expect to exist in languages. If it is true that languages universally have these two types of quantity expressions, this forces them to have nouns with count meanings and allows them to have nouns with meanings that are not compatible with expressions that presuppose countability. This means that 'mass only' languages are not possible, while 'count only' languages could exist, and Yudja might well be an example of such a language (Lima 2014).

The choices that languages make with respect to possible count meanings are often ontologically motivated, in particular in cases where nouns have a 'naturally individuated' referent, such as nouns denoting clearly delimited objects or animate individuals. However, ontology does not provide a means to predict the properties of a noun, which are to a large extent arbitrary. The substance water may be mass from an ontological point of view, but languages such as Yudja and Nez Perce use it with a count meaning that the English word water cannot get. Similarly, languages differ in terms of the mass meanings they allow or do not allow for nouns that denote naturally countable objects or individuals. In addition to this, count meanings can be abstract in the sense that the individual units do not need to be clearly individuated in the actual world, as can be illustrated by measure words and abstract nouns on the one hand, and the acquisition of abstract meaning on the other.

In the next section, I will turn to a different and more tentative way in which quantity expressions and word meanings interact, and argue that languages can make use of the system of quantity expressions they dispose of in order to mark the atomic individuals that are present in a count meaning as more or less salient.

\subsection{Individuation Boosting and Degrees of Individuation}

In this section, we will briefly explore the idea that the presence of an expression that presupposes units that can be counted triggers an effect of what I will call "individuation boosting." In several cases where subtle 
distinctions in the prominence of individuation are made, these distinctions seem to correlate with the presence vs. absence of count quantity expressions. For instance, nouns such as furniture are felt as less individuated than regular count nouns, and do not take number marking. Similarly, the data from the experiments of Lima (2014) described above show that bitu 'more' does not require a count reading while $\ddot{x} x i b i ̈$ 'many' does. The hypothesis of individuation boosting attributes these effects to the absence vs. presence of the presupposition of count meaning, which is introduced by count quantity expressions. The idea of the effect of individuation boosting is quite simple. A noun with a count meaning introduces individuals. If, in addition, there is a linguistic expression in the context that requires the noun to have a count meaning, this makes the presence of the individuals more salient. ${ }^{29}$

Let us first turn to the contrasts between bitu 'more' and itxibï 'many'. Even though there are good reasons to assume that all nouns have count meaning in Yudja, an interpretation in terms of the number of items is only required in the case of itxïbï. The Yudja data differ in this respect from data with more books, which despite the fact that more is a non-count quantity expression triggers an evaluation in terms of the number of books. However, contrary to Yudja, English is a language with obligatory number marking. The difference between the two languages can be accounted for if we assume that the obligatory evaluation in terms of number is triggered by the presence of a count quantity expression. This hypothesis can be tested on the basis of Brazilian Portuguese.

Brazilian Portuguese is a language with optional number marking with a lexical distinction between mass and count nouns (see Ferreira forthcoming, for an overview):
a. duas menina(s) [Brazilian Portuguese] two girls
b. \#duas areia(s)
two sands

If a count noun is combined with an expression that does not require number marking, such as mais, number marking may be present or absent. In the following examples, taken from Beviláqua and Pires de Oliveira (2014), the first sentence permits both an evaluation in terms of volume and in terms of number while the second triggers obligatorily a reading in terms of number (see also Pires de Oliveira and Rothstein 2011). Beviláqua and Pires de

\footnotetext{
29 Note that the idea of individuation boosting implies a hybrid relation between language and cognition, as it implies a strong association between the linguistic property of countability and the cognitive concept of individuation, despite the fact that linguistic structures that involve counting permit to abstract away from individuation (e.g., two/many liters of water).
} 
Oliveira (2014) present experimental data from Beviláqua (2014) that confirm this general pattern: as soon as a number marker is present somewhere in the structure, quantity judgments are almost exclusively made on the basis of number, while in the absence of the plural marker interpretations in terms of volume are permitted (though not preferred).
a. João tem
mais livro
que a Maria.
João has.PRS.3SG
more book
than the Maria
b. João tem
mais livros
que a Maria.
João has.PRS.3SG
more book-PL than the Maria

The patterns in Brazilian Portuguese and Yudja show that individuation originating from the lexical meaning of a noun is enough for obtaining an evaluation in terms of number (cf. the original experiment of Barner and Snedeker 2005). ${ }^{30}$ Under the hypothesis of individuation boosting, the presence of an expression that presupposes countability makes the individuated reading even more salient, as a result of which an evaluation in terms of volume becomes virtually impossible.

A second example of a phenomenon that could be attributed to individuation boosting is the use of the quantity expression $h o u^{2} d o^{l}$ 'a lot', which optionally combines with a classifier (Cheng et al. 2012):

$$
\begin{array}{llll}
\text { hou }^{2} \mathrm{do}^{1} & \text { bun } \left.^{2}\right) & \mathrm{syu}^{1} & \text { [Cantonese] } \\
\text { a lot } & \mathrm{CL}^{\text {volume }} & \text { book } &
\end{array}
$$

As expected, the books are more clearly individuated when the classifier is present. For instance, if the noun phrase is used to refer to the books in a library, the classifier will normally be absent. In order to describe books on a table, which can clearly be individualized, the classifier will be used.

A different domain where the idea of individuation boosting could be exploited is the lexicon. As indicated above, some lexical systems have number marking on some nouns and not on others. From the perspective of individuation boosting, this would be expected to correlate with higher and lower individuation. Whereas nouns that exceptionally lack number marking (e.g., furniture in English) are expected to correspond to a low degree of individuation, nouns that are exceptionally marked for plurality are expected to correspond to nouns with a high degree of individuation such as animate/ human nouns (cf. Smith-Stark 1974).

The concept of individuation boosting is related to the recent proposals of Grimm (2018), who argues in favor of distinguishing degrees of individuation

${ }^{30}$ An unpublished quantity judgment experiment presented by Scott Grimm and Beth Levin at Sinn und Bedeutung 16, comparing pairs such as jewels and jewelry, showed that the presence of plural morphology correlated with the necessity of an evaluation in terms of number, in line with the Brazilian Portuguese data. 
in natural language. Under the hypothesis of individuation boosting, the type of system that is at the basis of the linguistic expression of degrees of individuation might be severely constrained: in this latter view, degrees of individuation are the result of possibilities that the lexicon of a particular language offers for creating structures with and without count quantity expressions. Obviously, more research is needed to further exploit this idea.

\subsection{Conclusions}

This chapter studied the count/mass distinction from the perspective of quantity expressions. The properties of quantity expressions can only be understood in the context of the quantity system of which they are part. Language-specific properties of quantity expressions and the ways in which they interact with each other and with the possible noun meanings of the language they occur in are at the basis of the large amount of variation found in the domain of the count/mass distinction.

The main claim defended in this chapter is that, behind this linguistic variation, all languages present a distinction between count vs. non-count quantity expressions, which is at the basis of the count/mass distinction across languages. These two types of quantity expressions can be seen as linguistic reflections of numerical magnitude representation (Dehaene 1997; Feigenson et al. 2004) and general magnitude representation (Lourenco and Longo 2011), respectively. Whereas count quantity expressions presuppose countability and therefore only combine with expressions that may have a count meaning, noncount quantity expressions do not introduce such a presupposition, and therefore do not impose restrictions on the count (non-vague atoms) or mass (vague atoms/divisivity) meaning of the nouns they combine with. Quantity expressions that typically combine with mass nouns (e.g., a bit) are claimed to be a special type of non-count quantity expressions. They are analyzed in terms of blocking rather than in terms of sensitivity to the presence of mass meaning. As a consequence, the basic distinction between types of quantity expressions is a two-way distinction, and the count/mass distinction is asymmetric in the sense that quantity expressions make reference to count meaning but not to the absence thereof. Cross-linguistic evidence for this generalization based on different types of quantity systems was presented in Section 2.2.

The basic opposition between two types of quantity expressions - ones that need count meanings and ones that are indifferent towards the presence or absence of count meanings - and the hypothesis that these two types are crosslinguistically available, makes predictions on the availability of count and mass meanings across languages. If languages always dispose of expressions that can only be combined with nouns that (can) have a count meaning, count meaning necessarily exists across languages and 'mass only' languages are not 
available. 'Count only' languages, on the other hand, are not incompatible with the types of quantity expressions that are found. If it is correct that quantity expressions that presuppose mass meaning do not exist, languages in which all nouns always have a count denotation are predicted to be possible. As shown by Lima (2014), Yudja seems to be a candidate for such a language. As the examples of count meaning show, there is a large amount of lexical crosslinguistic variation in this domain, which is currently not well understood.

Finally, I suggested that the presence of a grammatical expression that presupposes countability may introduce an effect of individuation boosting. The ways in which this effect shows up in a particular language depend on the specific properties of the quantity expressions and the available noun meanings in that language. I gave several examples of phenomena that could be understood in terms of individuation boosting, and I consider this to be an important domain for further research.

\section{REFERENCES}

Bach, Elke, Eloise Jelinek, Angelika Kratzer, and Barbara Partee (2013). Quantification in Natural Languages, Vol. 54. Dordrecht: Springer.

Bale, Alan, and David Barner (2009). The interpretation of functional heads: Using comparatives to explore the mass/count distinction. Journal of Semantics 26.3: 217-252.

Bale, Alan, and Jessica Coon (2014). Classifiers are for numerals, not for nouns: Consequences for the mass/count distinction. Linguistic Inquiry 45.4: 695-707.

Barner, David, and Jesse Snedeker (2005). Quantity judgments and individuation: Evidence that mass nouns count. Cognition 97: 41-46.

Beviláqua, Kayron (2014). Nomes nus e nomes plurais: Um experimento sobre a distinção contável-massivo no PB. MA Thesis, Universidade Federal do Paraná.

Beviláqua, Kayron, and Roberta Pires de Oliveira (2014). Brazilian bare phrases and referentiality: Evidences from an experiment. Revista Letras 90: 253-275.

Borer, Hagit (2005). Structuring Sense Volume I: In Name Only. Oxford: Oxford University Press.

Brooks, Neon, Amanda Pogue, and David Barner (2011). Piecing together numerical language: Children's use of default units in early counting and quantification. Developmental Science 14: 44-57.

Cabredo Hofherr, Patricia (forthcoming). Nominal number morphology. In Patricia Cabredo Hofherr and Jenny Doetjes (eds.), The Oxford Handbook of Grammatical Number. Oxford: Oxford University Press.

Chao, Yuen Ren (1968). A Grammar of Spoken Chinese. Berkeley, CA: University of California Press.

Cheng, Chung-Ying (1973). Comments on Moravcsik's paper. In Jaakko Hintikka, Julius Moravcsik, and Patrick Suppes (eds.), Approaches to Natural Language, pp. 286-288. Dordrecht: Reidel.

Cheng, Lisa, and Rint Sybesma (1998). Yi-wan tang, yi-ge tang: Classifiers and massifiers. The Tsing Hua Journal of Chinese Studies 28.3: 385-412. 
(1999). Bare and not so bare nouns and the structure of NP. Linguistic Inquiry 30: 509-542.

(2005). Classifiers in four varieties of Chinese. In Guglielmo Cinque and Richard S. Kayne (eds.), The Oxford Handbook of Comparative Syntax, pp. 259-292. Oxford: Oxford University Press.

Cheng, Lisa, Jenny Doetjes, and Rint Sybesma (2008). How universal is the universal grinder? In Marjo van Koppen and Bert Botma (eds.), Linguistics in the Netherlands 2008, pp. 50-62. Amsterdam: John Benjamins.

Cheng, Lisa, Jenny Doetjes, Rint Sybesma, and Roberto Zamparelli (2012). On the interpretation of number and classifiers. Italian Journal of Linguistics 24: 175-194.

Chierchia, Gennaro (1998a). Plurality of mass nouns and the notion of "semantic parameter." In Susan Rothstein (ed.), Events and Grammar: Studies in Linguistics and Philosophy Vol. 7, pp. 53-103. Dordrecht: Kluwer.

(1998b). Reference to kinds across languages. Natural Language Semantics 6.4: 339-405.

(2010). Mass nouns, vagueness and semantic variation. Synthese 174.1: 99-149.

Corbett, Greville (2000). Number. Cambridge: Cambridge University Press.

Cowper, Elizabeth, and Daniel Currie Hall (2012). Aspects of individuation. In Diane Massam (ed.), Count and Mass across Languages, pp. 27-53. Oxford: Oxford University Press.

Deal, Amy Rose (2017). Countability distinctions and semantic variation. Natural Language Semantics 25: 125-171.

Dehaene, Stanislas (1997). The Number Sense. Oxford: Oxford University Press.

Denny, J. Peter (1986). The semantic role of noun classifiers. In Colette Craig (ed.), Noun Classes and Categorization, pp. 279-308. Amsterdam: John Benjamins.

Di Sciullo, Anna-Maria, and Edwin S. Williams (1987). On the Definition of Word. Cambridge, MA: MIT Press.

Doetjes, Jenny (1997). Quantifiers and Selection. On the Distribution of Quantifying Expressions in French, Dutch and English. The Hague: HAG.

(2008). Adjectives and degree modification. In Louise McNally and Christopher Kennedy (eds.), Adjectives and Adverbs: Syntax, Semantics and Discourse, pp. 123-155. Oxford: Oxford University Press.

(2010). Mismatches in the lexicon. Paper presented at Conference on Empirical, Theoretical and Computational Approaches to Countability in Natural Language, Bochum.

(2012). Count/mass distinctions across languages. In Claudia Maienborn, Klaus von Heusinger, and Paul Portner (eds.), Semantics: An International Handbook of Natural Language Meaning, pp. 2559-2580. Berlin: De Gruyter.

(2017a). Measure words and classifiers. Revista Letras 96: 291-308.

(2017b). The count/mass distinction in grammar and cognition. Annual Review of Linguistics 3: 199-217.

(2017c). Noun phrase. In Rint Sybesma (ed.), Encyclopedia of Chinese Language and Linguistics. Leiden: Brill.

Dryer, Matthew (2005). Coding of nominal plurality. In Martin Haspelmath, Matthew S. Dryer, David Gil, and Bernard Comrie (eds.), The World Atlas of Language Structures, pp. 138-141. Oxford: Oxford University Press. 
Farkas, Donka, and Henriëtte de Swart (2010). The semantics and pragmatics of plurals. Semantics and Pragmatics 3: 1-54.

Feigenson, Lisa, Stanislas Dehaene, and Elizabeth Spelke (2004). Core systems of number. Trends in Cognitive Sciences 8: 307-314.

Ferdinand, Astrid (1996). The Development of Functional Categories. PhD Thesis, Leiden University.

Ferreira, Marcelo (forthcoming). Bare nominals in Brazilian Portuguese. In Patricia Cabredo Hofherr and Jenny Doetjes (eds.), Oxford Handbook of Grammatical Number. Oxford: Oxford University Press.

Franz, Donald G., and Norma J. Russell (1995). Blackfoot Dictionary of Stems, Roots and Affixes, 2nd ed. Toronto: University of Toronto Press.

Gathercole, Virginia (1985). "He has too much hard questions." The acquisition of the linguistic mass-count distinction in much and many. Journal of Child Language 12: $395-415$.

Gillon, Brendan S. (2012). Mass terms. Philosophy Compass 7: 712-730.

Grimm, Scott (2012). Number and Individuation. PhD Dissertation, Stanford University.

(2014). Individuating the abstract. Paper presented at Sinn und Bedeutung 18, University of the Basque Country, Vitoria, Spain.

(2018). Grammatical number and the scale of individuation. Language 94.3: 527-574.

Grinevald, Colette (2005). Classifiers. In C. Lehmann, G. Booij, and J. Mugdan (eds.), Morphology: A Handbook on Inflection and Word Formation, pp. 1016-1031. Berlin: Walter de Gruyter.

Hamon, Roparz (1984). Grammaire bretonne. Saint Malo: Al liamm.

Harrison, Sheldon, and Salich Albert (1976). Mokilese Reference Grammar. Honolulu, HI: University Press of Hawaii.

Heim, Irene (1991). Artikel und Definitheit. In Arnim von Stechow and Dieter Wunderlich (eds.), Semantics: An International Handbook of Contemporary Research, pp. 487-535. Berlin: Walter de Gruyter.

Hsieh, Miao-Ling (2008). The Internal Structure of Noun Phrases in Chinese. Books Series in Chinese Linguistics, No. 2. Taipei: Crane Publishing.

Iljic, Robert (1994). Quantification in Mandarin Chinese: Two markers of plurality. Linguistics 32: 91-116.

Krifka, Manfred (1992). Thematic relations as links between nominal reference and temporal constitution. In Ivan Sag and Anna Szabolcsi (eds.), Lexical Matters, pp. 29-53. Stanford, CA: CSLI.

Lehrer, Adrienne (1986). English classifier constructions. Lingua 68: 109-148.

Li, Peggy, Yarrow Dunham, and Susan Carey (2009). Of substance: The nature of language effects on entity construal. Cognitive Psychology 58: 487-524.

Li, XuPing (2013). Numeral Classifiers in Chinese. Berlin: De Gruyter.

Lima, Suzi (2010). About the count-mass distinction in Yudja: A description. In Beth Rogers and Anita Szakay (eds.), Papers for WSCLA 15: The Fifteenth Workshop on Structure and Constituency in Languages of the Americas, pp. 157-164. Ottawa: University of British Columbia Working Papers in Linguistics.

(2012). Numerals and the universal packager in Yudja (Tupi). Paper presented at SULA 6, Manchester, UK. 
(2014). The Grammar of Individuation and Counting. PhD Thesis, University of Massachusetts Amherst.

Link, Godehard (1983). The logical analysis of plurals and mass terms: A latticetheoretical approach. In Rainer Baüerle, Christoph Schwarze, and Arnim von Stechow (eds.), Meaning, Use, and Interpretation of Language, pp. 302-323. Berlin: de Gruyter.

Lourenco, Stella F., and Matthew R. Longo (2011). Origins and development of generalized magnitude representation. In Stanislas Dehaene and Elizabeth M. Brannon (eds.), Space, Time, and Number in the Brain: Searching for the Foundations of Mathematical Thought, pp. 225-244. Amsterdam: Elsevier.

Mathieu, Éric (2012). On the mass/count distinction in Ojibwe. In Diane Massam (ed.), Count and Mass across Languages, pp. 172-198. Oxford: Oxford University Press.

Nicolas, David (2004). Is there anything characteristic about the meaning of a count noun? Revue de la lexicologie 18-19.

Ojeda, Almerindo (1993). Linguistic Individuals. Stanford, CA: CSLI.

Pelletier, Francis J., and Lenhart Schubert (1989). Mass expressions. In D. Gabbay and F. Guenthner (eds.), Handbook of Philosophical Logic. Volume IV: Topics in the Philosophy of Language, pp. 327-408. Dordrecht: Reidel.

Pelletier, Francis J. (2012). Lexical nouns are both +mass and +count, but they are neither +mass nor + count. In Diane Massam (ed.), Count and Mass across Languages, pp. 9-26. Oxford: Oxford University Press.

Pica, Pierre, Cathy Lemer, Véronique Izard, and Stanislas Dehaene (2004). Exact and approximate arithmetic in an Amazonian indigene group. Science 306: 499-503.

Pinker, Steven (1995). The Language Instinct: The New Science of Language and Mind. London: Penguin.

Pires de Oliveira, Roberta, and Susan Rothstein (2011). Bare singular noun phrases are mass in Brazilian Portuguese. Lingua 121: 2153-2175.

Rothstein, Susan (2009). Towards a grammar of counting and measuring. Paper presented at Workshop on Nominal and Verbal Plurality, Paris, France.

(2010a). Individuating and measure readings of classifier constructions: Evidence from Modern Hebrew. Brill's Annual of Afroasiatic Languages and Linguistics 1: $106-145$.

(2010b). The semantics of count nouns. In Maria Aloni and Katrin Schulz (eds.), Amsterdam Colloquium 2009, pp. 395-404. Berlin: Springer-Verlag.

(2011). Numbers: counting, measuring and classifying. Paper presented at Sinn und Bedeutung 16, Utrecht University.

(2017). Semantics for Counting and Measuring: Key Topics in Semantics and Pragmatics. Cambridge: Cambridge University Press.

Rullmann, Hotze, and Aili You (2006). General number and the semantics and pragmatics of indefinite bare nouns in Mandarin Chinese. In K. von Heusinger and K. Turner (eds.), Where Semantics Meets Pragmatics, pp. 175-196. Amsterdam: Elsevier.

Sauerland, Uli (2003). A new semantics for number. In R. Young and Y. Zhou (eds.), Proceedings of SALT xiII, pp. 258-275. Ithaca, NY: Cornell University Press.

Saussure, Ferdinand de (1916). Cours de linguistique générale. Edited by C. Bally and A. Sechehaye, assisted by A. Riedlinger. Lausanne and Paris: Payot. 
Schvarcz, Brigitta R., and Susan Rothstein (2017). Hungarian classifier constructions, plurality and the mass-count distinction. In Harry van den Hulst and Anikó Lipták (eds.), Approaches to Hungarian: Volume 15: Papers from the 2015 Leiden Conference, pp. 103-208. Amsterdam and Philadelphia, PA: John Benjamins.

Shipley, Elizabeth F., and Barbara Shepperson (1990). Countable entities: Developmental changes. Cognition 34: 109-136.

Smith-Stark, T. Cedric (1974). The plurality split. Paper presented at the Chicago Linguistic Society.

Spelke, Elizabeth, and Katherine Kinzler (2007). Core knowledge. Developmental Science 10: 89-96.

Wiese, Heike (2003). Numbers, Language and the Human Mind. Cambridge: Cambridge University Press.

Wiggins, David (1980). Sameness and Substance. Oxford: Blackwell.

Wilhelm, Andrea (2008). Bare nouns and number in Denë Suliné. Natural Language Semantics 16: 39-68.

Wiltschko, Martina (2008). The syntax of non-inflectional plural marking. Natural Language \& Linguistic Theory 26: 639-694.

(2012). Decomposing the mass/count distinction: Evidence from languages that lack it. In Diane Massam (ed.), Count and Mass across Languages, pp. 46-170. Oxford: Oxford University Press

Zhang, Niina Ning (2012). Numeral classifier structures in Mandarin Chinese. Ms., National Chung Cheng University.

(2013). Classifier Structures in Mandarin Chinese. Berlin: De Gruyter.

Zucchi, Sandro, and Michael White (2001). Twigs, sequences and the temporal constitution of predicates. Linguistics and Philosophy 24.2: 223-270. 